\title{
Pharmacokinetics and pharmacodynamics of artesunate and dihydroartemisinin following oral treatment in pregnant women with asymptomatic Plasmodium falciparum infections in Kinshasa DRC
}

Marie A Onyamboko ${ }^{1}$, Steven R Meshnick ${ }^{2 *}$, Lawrence Fleckenstein ${ }^{3}$, Matthew A Koch $^{4}$, Joseph Atibu', Victor Lokomba', Macaya Douoguih ${ }^{5}$, Jennifer Hemingway-Foday ${ }^{4}$, David Wesche $^{6}$, Robert W Ryder ${ }^{7}$, Carl Bose ${ }^{8}$, Linda L Wright ${ }^{9}$, Antoinette K Tshefu ${ }^{1}$, Edmund V Capparelli ${ }^{7}$

\begin{abstract}
Background: In many malaria-endemic countries, increasing resistance may soon compromise the efficacy of sulphadoxine-pyrimethamine (SP) for intermittent preventative treatment (IPT) of malaria in pregnancy. Artemisininbased IPT regimens represent a promising potential alternative to SP. Pharmacokinetic and safety data supporting the use of artemisinin derivatives in pregnancy are urgently needed.

Methods: Subjects included pregnant women with asymptomatic falciparum parasitaemia between 22-26 weeks $(n=13)$ or 32-36 weeks gestation $(n=13)$, the same women at three months postpartum, and 25 non-pregnant parasitaemic controls. All subjects received $200 \mathrm{mg}$ orally administered AS. Plasma total and free levels of AS and its active metabolite DHA were determined using a validated LC-MS method. Non-compartmental pharmacokinetic analysis was performed using standard methods.
\end{abstract}

Results: All pregnant women delivered live babies. The median birth weight was 3025 grams [range 2130, 3620]; 2 of 26 babies had birth weights less than 2500 grams. Rates of parasite clearance by 12 hours post-dose were high and comparable among the groups. Rapid elimination of AS was observed in all three groups. The $90 \% \mathrm{Cl}$ for the pregnancy:postpartum ratio of geometric means for total and free AUC fell within the pre-specified $0.66-1.50$ therapeutic equivalence interval. However, more pronounced pharmacokinetic differences were observed between the pregnancy and control subjects, with the $90 \% \mathrm{Cl}$ for the pregnancy:control ratio of geometric means for both total $0.68(90 \% \mathrm{Cl} 0.57-0.81)$ and free AUC $0.78(90 \% \mathrm{Cl} 0.63-0.95)$ not fully contained within the $0.66-1.50$ interval. All subjects cleared parasites rapidly, and there was no difference in the percentage of women who were parasitaemic 12 hours after dosing.

Conclusions: A single dose of orally administered AS was found to be both effective and without adverse effects in this study of second and third trimester pregnant women in the DRC. Although DHA AUC during pregnancy and postpartum were similar, the AUC for the pregnant group was less than the non-pregnant controls. The findings of this study suggest that additional studies on the pharmacokinetics of AS in pregnant women are needed.

Trial Registration: ClinicalTrials.gov: NCT00538382

\footnotetext{
* Correspondence: meshnick@unc.edu

UNC Gillings School of Global Public Health Department of Epidemiology,

3301 MHRCChapel Hill NC 27599-7435, USA

Full list of author information is available at the end of the article
} 


\section{Background}

Pregnant women are particularly susceptible to malaria, which can lead to intrauterine growth restriction, low birth weight, prematurity, and other poor birth outcomes [1-7]. In order to protect pregnant women against malaria, WHO recommends intermittent preventive treatment (IPT) with sulphadoxine-pyrimethamine (SP) in stable transmission areas. Unfortunately, rates of SP resistance are now quite high in most of the world. For example, Plasmodium falciparum resistance to SP is greater than $57 \%$ in the eastern part of the Democratic Republic of Congo (DRC) [8-10]. The growing threat of SP resistance has resulted in substantial concern that SP may become ineffective for IPT in the very near future. Therefore, there is an urgent need to identify efficacious alternative drug regimens $[11,12]$.

Artemisinin-based combination therapy (ACT) is the current first-line treatment for acute malaria in most malaria-endemic countries [1]. Currently, recommended ACT dosage regimens are based on studies conducted in non-pregnant patients; however, the pharmacokinetics of many drugs is altered during pregnancy. WHO endorses the use of ACT for patients in the second and third trimesters of pregnancy with acute uncomplicated falciparum malaria [13], but specific dosing recommendations for pregnant women have not been developed due to insufficient pharmacokinetic data in this population. There are also safety concerns regarding the use of artemisinin derivatives in pregnancy, particularly in the first trimester. In response to evidence from animal studies of artemisininassociated embryotoxicity [14], WHO guidelines constrain the use of these derivatives in the first trimester to cases of therapeutic failure with alterative agents [13].

Additional pharmacokinetic and safety information regarding the use of artemisinin derivatives in pregnancy are needed [15-18]. To date, no pharmacokinetic study for an artemisinin derivative has been conducted that included postpartum or non-pregnant controls. Additionally, no such pharmacokinetic study has been conducted with asymptomatic parasitaemic women, the candidate population for IPT. This paper reports the results of a safety and pharmacokinetic study of a single oral dose of artesunate (AS) given to asymptomatic but parasitaemic pregnant women with $P$. falciparum infection, the same women three months postpartum, and a parallel parasitaemic non-pregnant control group.

\section{Methods}

\section{Study population}

The study was conducted at Maternité des Soeurs de Saint Marc de Kingasani, the largest maternity service in Kinshasa. All women from 18 to 40 years of age presenting for antenatal care at less than 22 weeks of gestation assessed on last menstrual period (LMP), were screened for eligibility. Gestational age (GA) was confirmed by ultrasound using the Hadlock method [19]. Women with gestational ages between 8 and 21 weeks (inclusive) were invited to participate in the study. Women were asked during to return during the second trimester of pregnancy (22-26 weeks GA); those not enrolled during the second trimester were screened again during the third trimester (32-36 weeks). Eligibility for the study was established during the women's return visits. Eligibility criteria included the following: no fever (temperature $<37.5^{\circ} \mathrm{C}$ ), infection with $P$. falciparum (parasite count between 200 to $<300,000$ parasites $/ \mu \mathrm{L}$ ), haematocrit $\geq 30 \%$, HIV seronegativity, and the absence of other major medical problems (e.g. diabetes, chronic hypertension, etc.).

To determine if women met the eligibility criteria, a complete medical history and physical examination was performed by a study physician; sociodemographic data was collected by a study nurse. Haematocrit was measured using a microhaematocrit centrifuge (Hawksley Haematospin 1400, Hawksley \& Sons, Ltd, UK). Thick and thin blood films were stained with Giemsa and then read to determine parasite species and the density of P. falciparum asexual stages. Parasite density, based on examination of at least 200 high-power microscope fields, was calculated as (\# trophozoites/\#white blood cells) "6000. Human Immunodeficiency Virus (HIV) serology was determined using the Determine 1/2 HIV Test Kit (Inverness Medical Professional Diagnostics, Princeton, $\mathrm{NJ})$. Liver function was assessed by measuring aspartate aminotransferase (AST) and alanine aminotransferase (ALT) in plasmaPiccolo Portable Chemistry Analyser, Abaxis, USA). Alpha-1-Acid glycoprotein was determined in serum samples using radial immunodiffusion (Kent Laboratories, Bellingham, WA, USA).

There were two groups of non-pregnant controls. One group of controls $(\mathrm{n}=26)$ was comprised of the pregnant study subjects at their three month postpartum visits. The second group of controls $(n=25)$ consisted of malaria-infected, asymptomatic non-pregnant women. Women were recruited from the area around the hospital and from one suburban health center. Interested women were directed to the research center where they were tested to assess eligibility using the same criteria as the pregnant cases.

In order to confirm malaria infection, DNA was later extracted from dried blood spots and analysed by real time PCR using pan-species primers and probe [20].

\section{Ethical clearance and consent}

The study protocol was approved by the ethics committees of Kinshasa School of Public Health, the University of North Carolina at Chapel Hill, and RTI International. The study was first introduced to the pregnant women 
during their first antenatal clinic (ANC) visit in order to obtain consent for early ultrasound screening. Consent for laboratory screening was obtained from these women when they returned during their second or third trimester of pregnancy, and from the non-pregnant controls at the time of enrollment. Consent for the two days inpatient was obtained from all subjects after determining eligibility.

\section{Treatment and sampling}

Study subjects received an oral dose of $200 \mathrm{mg}$ AS as four $50 \mathrm{mg}$ tablets (manufactured by Guilin Pharmaceutical Co. Ltd, Guangxi, Republic of China) after a four-hour fasting period. The four tablets were given orally with $240 \mathrm{~mL}$ water under medical supervision. A catheter was inserted into a forearm vein for pharmacokinetic sample collection and flushed after each blood draw with saline solution. Blood $(5 \mathrm{ml})$ was drawn from the IV catheter within a 30 minute period before drug intake and then at the following times after AS intake: 0.25, 0.5, 0.75, 1, 1.5 $2,3,4,6$, and 8 hours. Sodium fluoride/potassium oxalate was used as an anticoagulant. Blood for malaria smears were taken by finger prick at pre-dose and at $12,24,30$, 36,42 and 48 hours post-dose. Malaria smears were also performed on days 7, 14 and 28 .

Blood samples were centrifuged immediately at $-4^{\circ} \mathrm{C}$ $(1,100 \times \mathrm{g} /$ or $2600 \mathrm{rpm}, 10 \mathrm{~min}$; Eppendorf refrigerated centrifuge) and the plasma initially stored in liquid nitrogen before being transferred to a $-80^{\circ} \mathrm{C}$ freezer. Twenty-four hours after receiving AS, malaria-infected women received $1725 \mathrm{mg}$ SP to complete malaria treatment in accordance with National Malaria Control Program guidelines. The persistence of malaria infection and adverse events were tracked for 28 days after SP administration. Babies born from the pregnant women cohort were followed until one year of age and development assessed.

\section{Drug assay}

Plasma concentrations of AS and its active metabolite dihydroartemisinin (DHA) were determined using a validated liquid chromatography-mass spectrometric method described by Naik et al [21] with slight modifications. Briefly, AS, DHA and the internal standard artemisinin were extracted from $0.25 \mathrm{~mL}$ of human plasma using solid phase extraction. The reconstituted extracts were chromatographed isocratically and the compounds detected and quantified by mass spectroscopy. The lower limit of quantification for both AS and DHA was $1 \mathrm{ng} / \mathrm{mL}$. Unbound DHA was assayed using ultrafiltration.

\section{Pharmacokinetic and statistical analysis}

Plasma AS and DHA concentration data were analyzed by noncompartmental methods using the program
WinNonlin, version 5.2 (Pharsight, Mountain View, CA). Specifically, $C_{\max }$ and $\mathrm{T}_{\max }$ were taken from observed concentrations and the terminal slope, $\lambda_{z}$, determined for DHA by non-linear regression of the terminal portion of the concentration vs. time profile using a $1 / \mathrm{Y}$ weighting. The DHA elimination half-life was calculated as $0.693 / \lambda_{\mathrm{z}}$. The area under the DHA concentration-time curve $\left(\mathrm{AUC}_{\text {total }}\right)$ was determined using the trapezoidal method and total DHA concentrations, with extrapolation of the AUC after the final concentration estimated as $C_{\text {last }} / \lambda_{\mathrm{z}}$. The apparent plasma clearance $(\mathrm{CL} / \mathrm{F})$ was determined as Dose/AUC $\mathrm{Atal}_{\text {tal }}$ and apparent volume of distribution $(\mathrm{Vd} / \mathrm{F})$ calculated as Dose $/\left(\lambda_{\mathrm{z}} * \mathrm{AUC}_{\text {total }}\right)$ where the AS dose was assumed to be totally and exclusively converted to DHA. Thus the DHA dose was assumed to be equal to the AS dose on a molar basis (DHA dose = AS dose * (284.35/384.42)), the latter ratio representing the molecular weights of DHA and AS. The DHA free fraction (FF) was determined as the ratio of unbound/total drug concentration at each time point where both measurements were collected, with mean FF calculated for each participant within a pharmacokinetic visit. The area under the unbound DHA concentration-time curve $\left(\mathrm{AUC}_{\text {free }}\right)$ was calculated as $\mathrm{FF}^{*} \mathrm{AUC}_{\text {total }}$. The AUC of AS was also determined using the trapezoidal method. Concentrations below the lower limit of quantification were assigned a value of zero. The terminal slope of the AS concentration profile could not be estimated due to the limited samples after $C_{\max }$ with concentrations above the lower limit of quantification.

The primary pharmacokinetic outcome measured to assess dosing adequacy was DHA AUC free. The AUCs for unbound DHA during pregnancy and postpartum were compared using each subject as her own control. The ratio of the AUC during pregnancy to the AUC at postpartum (after log transformation) was considered a measure of the impact of pregnancy on systemic exposure. The interval between population ratios of 0.66 and 1.5 was defined as an interval of "no effect" of pregnancy on pharmacokinetics. The "no effect" interval was selected based on the dose-ranging study by Angus and coworkers [22]. Their sigmoid $\mathrm{E}_{\max }$ pharmacodynamic model suggested that the dose with $50 \%$ maximal effect on parasite clearance time (PCT) was $1.46 \mathrm{mg} / \mathrm{kg}$ or $\sim 100 \mathrm{mg}$, with a sharp increase in response around this value (Hill slope coefficient of 10). Based on these data and available formulation strengths, we chose an exposure of $66 \%$ for non-pregnant women (equivalent to 132 $\mathrm{mg}$ ) as the lower bound of our no-effect window. If the 90\% confidence interval $(\mathrm{CI})$ of pregnancy/postpartum DHA $\mathrm{AUC}_{\text {free }}$ was determined to be within the 0.66 and 1.5 interval, then the DHA exposure was deemed as clinically equivalent between pregnancy and postpartum. 
Statistical analyses were performed using SAS/STAT software, version 9.2 (SAS Institute, Inc., Cary, NC, 2008). For comparisons involving non-compartmental parameters, $\mathrm{p}$-values provided with geometric mean estimates and $90 \%$ CIs were based on (paired or 2-sample) t-tests (on logged data, except as noted) and with medians were based on (signed rank or rank sum) Wilcoxon tests. Spearman correlations were used to look for associations among the pregnant and control population. All p-values were 2-sided.

\section{Results}

Patients

Between May 2007 and November 2008, 13 pregnant women were enrolled in their second trimester and 13 in their third trimester. Twenty-five non-pregnant women with asymptomatic falciparum malaria were also enrolled. The demographic and medical characteristics of the three groups are shown in Table 1. There were no significant differences among any of the three groups in age, height, or education level. All women had normal temperatures, normal blood pressures, a haematocrit $\geq 30 \%$, negative HIV tests result, normal physical exams and no histories of chronic illness or of drug intake (other than antipyretics). Pregnant women had a significantly lower haematocrit and higher parity.

The median parasite densities at screening were 528 parasites $/ \mu \mathrm{L}$ of blood (interquartile range: $372-842$ ) in the pregnant group and 807 parasites/ $\mu \mathrm{L}$ (interquartile range: 325 - 2215) in the non-pregnant group; these were not significantly different (Table 2 ). All were $P$. falciparum monoinfections, except for one pregnant case with a mixed infection ( $P$. falciparum and Plasmodium malariae). Antenatal women in Window 1 received slightly higher doses on a $\mathrm{mg} / \mathrm{kg}$ dosage than those in Window 2, but there were no significant differences between the pregnant women and their controls.

\section{Pharmacodynamics}

Parasitaemia was confirmed in all subjects by PCR at the time of recruitment. However, two pregnant women and 11 non-pregnant controls were microscopically aparasitaemic by the time the pharmacokinetic experiment started, usually a day later. Of the 24 pregnant women who were parasitaemic at $\mathrm{t}=0,21(87.5 \%)$ were aparasitaemic at 12 hrs (Table 2). Similarly, 13 of the 14 (93\%) non-pregnant controls with parasites at $\mathrm{t}=0$ were aparasitaemic at 12 hours. One pregnant woman was parasitaemic on day 28. Two others had gametocytes on day 7 , one of whom also had gametocytes on day 14. Two other women from the pregnant group were parasitaemic at three months postpartum; one of these had a mixed infection with (P. falciparum and P. malariae). There were no significant differences between pregnant cases and controls in the percentage of women who were non-parasitaemic at 12 hours (Table 2).

\section{Pharmacokinetics}

In all three groups, AS was rapidly hydrolyzed to DHA, with AS concentrations below the lower limit of quantification $(1 \mathrm{ng} / \mathrm{mL})$ after 4 hours in all but two samples. The median AS AUCs were 205, 132 and 187 ng"h/mL for pregnancy, postpartum and non-pregnant women, respectively, with AUCs ranging among the subjects by more than 17 -fold.

The median plasma concentration profiles of DHA in the three groups are shown in Figure 1. The pharmacokinetic parameter estimates for DHA are summarized in Table 3. The pregnancy:postpartum, pregnancy:control, and postpartum:control ratios of geometric means for those parameters are shown in Table 4. Most DHA pharmacokinetic parameters were similar during pregnancy and postpartum after accounting for the higher free fraction during pregnancy. The estimated geometric mean and $90 \% \mathrm{CI}$ for the ratio of the within-subject AUCs for free DHA for the women during pregnancy compared with three months postpartum was $0.99(0.85$, 1.15).

The median DHA AUC was significantly higher in the non-pregnant control group than in the pregnant group (2787 vs $1731 \mathrm{ng}$ " $\mathrm{h} / \mathrm{mL}$, respectively $\mathrm{p}=0.0018$; estimated ratio of geometric means, $0.68,90 \%$ CI [0.57, 0.81 ], $\mathrm{p}=0.0004$ ); the difference in $\mathrm{C}_{\max }$ did not reach statistical significance $(1285$ vs $905 \mathrm{ng}$ *h/mL respectively, $\mathrm{p}=0.24 ; 0.81[0.63,1.03], \mathrm{p}=0.15)$. The estimated ratio of geometric means for free DHA AUC in the pregnancy and control groups was $0.78,90 \% \mathrm{CI}$ $[0.63,0.95], \mathrm{p}=0.039$. The DHA free fraction was significantly higher in the pregnancy group than control groups but the free DHA AUC remained higher in nonpregnant than the pregnancy group.

The relationship between free DHA AUC and body weight is shown in Figure 2. Larger women had lower AUCs in the malaria infected groups as weight was inversely correlated with AUC $\left(\mathrm{r}^{2}=0.38, \mathrm{p}=0.001\right)$. Albumin and AGP levels were lower in pregnant women than in postpartum or non-pregnant controls $(\mathrm{p}=0.0003$ and 0.0038 , respectively, Additional file 1). These lower binding protein concentrations are likely responsible for the modest difference in the unbound DHA fraction.

\section{Safety}

All pregnancies were followed until delivery and resulted in singleton live births. There were no congenital abnormalities. The median birth weight was 3025 grams [range 2130, 3620] with 7.7\% (2/26) weighing $\leq 2500$ grams. Twenty-three of the 26 babies were followed 
Table 1 Demographic characteristics on admission of women with Plasmodium falciparum infection (pregnant cases and non-pregnant controls)

\begin{tabular}{|c|c|c|c|c|c|c|}
\hline \multirow[b]{2}{*}{ Characteristic } & \multicolumn{4}{|l|}{ Pregnant cases } & \multirow[b]{2}{*}{ Non-pregnant controls } & \multirow[b]{2}{*}{ P-valuet } \\
\hline & $\begin{array}{l}\text { Window } 1 \\
(22-26 \text { wks GA) }\end{array}$ & $\begin{array}{l}\text { Window } 2 \\
\text { (32-36 wks GA) }\end{array}$ & P-value* & All & & \\
\hline N & 13 & 13 & & 26 & 25 & \\
\hline Age (years) $\ddagger$ & $21.7 \pm 2.7$ & $26.6 \pm 4.4$ & 0.0065 & $24.2 \pm 4.4$ & $24.8 \pm 5.5$ & 0.79 \\
\hline Height $(m) \neq$ & $1.6 \pm 0.1$ & $1.6 \pm 0.1$ & 0.56 & $1.6 \pm 0.1$ & $1.6 \pm 0.1$ & 0.77 \\
\hline Weight $(\mathrm{kg}) \neq$ & $55.5 \pm 8.3$ & $63.0 \pm 7.2$ & - & - & $55.2 \pm 10.6$ & - \\
\hline Postpartum (3 months) weight (kg)‡ & $53.7 \pm 7.6$ & $58.0 \pm 4.3$ & 0.14 & $55.8 \pm 6.4$ & & 0.29 \\
\hline BMI $\left(\mathrm{kg} / \mathrm{m}^{2}\right) \ddagger$ & $21.2 \pm 2.8$ & $24.4 \pm 2.2$ & - & $22.7 \pm 3.0$ & $21.0 \pm 3.2$ & 0.055 \\
\hline Postpartum (3 months) BMI $\left(\mathrm{kg} / \mathrm{m}^{2}\right) \neq$ & $20.3 \pm 2.3$ & $22.6 \pm 1.7$ & 0.017 & $21.4 \pm 2.3$ & & 0.29 \\
\hline Education (years) $\ddagger$ & $9.0 \pm 3.6$ & $9.5 \pm 3.0$ & 0.57 & $9.2 \pm 3.3$ & $9.8 \pm 3.8$ & 0.73 \\
\hline Parity§ & $0(0-2)$ & $1(0-4)$ & 0.081 & $1(0-4)$ & $0(0-4)$ & 0.0013 \\
\hline Parity & & & 0.23 & & & 0.0002 \\
\hline 0 & $7(53.8)$ & $4(30.8)$ & & $11(42.3)$ & $23(92.0)$ & \\
\hline 1 & $5(38.5)$ & $3(23.1)$ & & $8(30.8)$ & $0(0.0)$ & \\
\hline 2 & $1(7.7)$ & $4(30.8)$ & & $5(19.2)$ & $1(4.0)$ & \\
\hline $3-4$ & $0(0.0)$ & $2(15.4)$ & & $2(7.7)$ & $1(4.0)$ & \\
\hline GA at ultrasound screening (weeks) $\neq$ & $18.9 \pm 1.5$ & $18.5 \pm 1.5$ & 0.41 & - & - & - \\
\hline GA at study screening (weeks)‡ & $22.4 \pm 0.8$ & $33.2 \pm 1.4$ & - & - & - & - \\
\hline Body temperature $\left({ }^{\circ} \mathrm{C}\right) \|$ & $\begin{array}{l}36.5 \\
(36.1-36.7)\end{array}$ & $\begin{array}{l}36.4 \\
(36.2-36.5)\end{array}$ & 0.66 & $\begin{array}{l}36.5 \\
(36.1-36.6)\end{array}$ & $\begin{array}{l}36.6 \\
(36.4-36.8)\end{array}$ & 0.044 \\
\hline Haematocrit (\%)\| & $\begin{array}{l}30.0 \\
(30.0-30.0)\end{array}$ & $\begin{array}{l}32.0 \\
(31.0-33.0)\end{array}$ & 0.035 & $\begin{array}{l}30.5 \\
(30.0-33.0)\end{array}$ & $\begin{array}{l}38.0 \\
(34.0-38.0)\end{array}$ & $<.0001$ \\
\hline Dosage $(\mathrm{mg} / \mathrm{kg}) \|$ & $\begin{array}{l}3.45 \\
(3.17-4.17)\end{array}$ & $\begin{array}{l}3.08 \\
(2.99-3.17)\end{array}$ & 0.017 & $\begin{array}{l}3.17 \\
(3.08-4.00)\end{array}$ & $\begin{array}{l}3.86 \\
(3.39-4.17)\end{array}$ & 0.061 \\
\hline
\end{tabular}

* Pregnant cases, Window 1 vs Window 2; Fisher's exact and Wilcoxon rank sum tests.

† All pregnant cases vs. nonpregnant controls; Fisher's exact and Wilcoxon rank sum tests.

‡ Values given as mean \pm standard deviation.

$\S$ Values given as median (range)

$\|$ Values given as median (interquartile range).

Table 2 Pharmacodynamics of AS in malaria-infected women

\begin{tabular}{|c|c|c|c|c|c|}
\hline \multirow[b]{2}{*}{ Time point } & \multicolumn{3}{|l|}{ Pregnant cases } & \multirow[b]{2}{*}{ Non-pregnant controls } & \multirow[b]{2}{*}{ P-value* } \\
\hline & $\begin{array}{l}\text { Window } 1 \\
\text { (22-26 wks GA) }\end{array}$ & $\begin{array}{l}\text { Window } 2 \\
\text { (32-36 wks GA) }\end{array}$ & All & & \\
\hline $\bar{N}$ & 13 & 13 & 26 & 25 & \\
\hline \multicolumn{6}{|l|}{ Screening } \\
\hline Parasitaemic - n (\%) & $13(100.0)$ & $13(100.0)$ & $26(100.0)$ & $25(100.0)$ & - \\
\hline Density (where $>0$ ) † & $\begin{array}{l}635 \\
(264-842)\end{array}$ & $\begin{array}{l}516 . \\
(404-659)\end{array}$ & $\begin{array}{l}528 \\
(372-842)\end{array}$ & $\begin{array}{l}807 \\
(325-2215)\end{array}$ & 0.21 \\
\hline \multicolumn{6}{|l|}{0 hours (AS dosing) } \\
\hline Parasitaemic - n (\%) & $13(100.0)$ & $11(84.6)$ & $24(92.3)$ & $14(56.0)$ & 0.0029 \\
\hline Density (where $>0$ ) † & $\begin{array}{l}414 \\
(179-857)\end{array}$ & $\begin{array}{l}183 \\
(130-788)\end{array}$ & $\begin{array}{l}247 \\
(151,828)\end{array}$ & $\begin{array}{l}371 \\
(124-957)\end{array}$ & 0.66 \\
\hline \multicolumn{6}{|l|}{12 hours } \\
\hline Parasitaemic - n (\%) & $3(23.1)$ & $0(0)$ & $3(11.5)$ & $1(4.0)$ & 0.61 \\
\hline Density (where $>0$ ) $†$ & $\begin{array}{l}87 \\
(44-286)\end{array}$ & $\begin{array}{l}- \\
-\end{array}$ & $\begin{array}{l}87 \\
(44-286)\end{array}$ & $\begin{array}{l}24 \\
-\end{array}$ & 0.44 \\
\hline
\end{tabular}

* All pregnant cases vs. nonpregnant controls; Pearson chi-square, Fisher's exact, and Wilcoxon rank sum tests.

† Values given as median (interquartile range). 


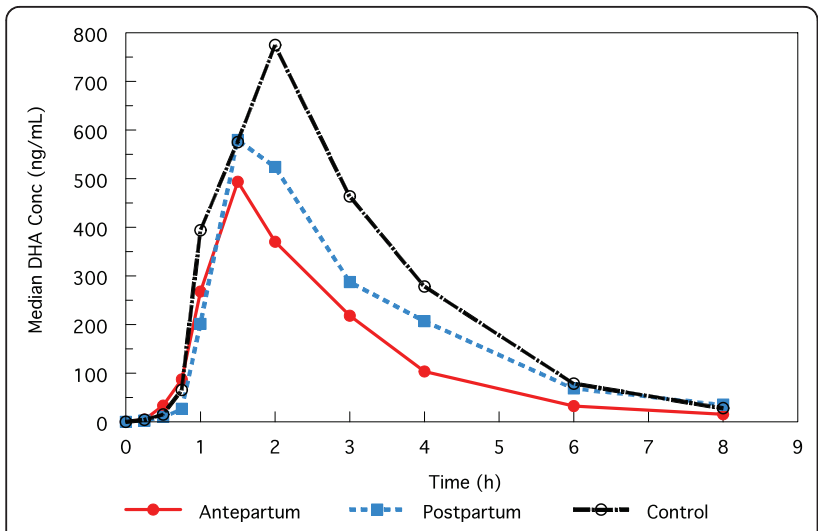

Figure 1 Median plasma concentration of DHA in pregnant, postpartum, and non-pregnant subjects.

until one year of age and at that time had normal physical and neurological development.

There were no adverse events observed in any subjects. Statistically significant increases in some laboratory parameters were observed (Additional file 1), but the magnitude of these changes was small. In some subjects, transient elevations of ALT and AST above the upper limits of normal were observed. However, as these elevations were less than twice the upper limits of normal, they were considered clinically insignificant.

\section{Discussion}

The study was conducted in the DRC, where high in vivo resistance to SP [8-10] could soon compromise the efficacy of SP for IPT in pregnancy. An IPT regimen incorporating an artemisinin derivative, such as AS, could provide a promising alternative to SP. However, despite the broad implementation of ACTs globally for treatment of acute falciparum malaria, questions remain regarding the safety, pharmacokinetics, and efficacy of artemisinin derivatives in pregnant women. The present study was designed to assess the safety and pharmacokinetics of AS in a population of asymptomatic parasitaemic women in the second and third trimesters of pregnancy, compared to the same women at three months postpartum and a control group of parasitaemic non-pregnant controls.

The pharmacokinetic analysis in this study indicates that in all three groups of women, AS was rapidly hydrolysed to its active metabolite DHA, becoming undetectable within 4 hours. This observed rapid AS disappearance is consistent with results previously

Table 3 DHA noncompartmental pharmacokinetic data in pregnant, postpartum, and non-pregnant women with Plasmodium falciparum infection

\begin{tabular}{|c|c|c|c|c|c|c|}
\hline \multirow[b]{2}{*}{ Parameters } & \multicolumn{2}{|c|}{ Pregnant cases } & \multirow[b]{2}{*}{$\begin{array}{l}\text { Non-pregnant } \\
\text { controls }\end{array}$} & \multirow[b]{2}{*}{$\begin{array}{l}\text { Ante vs. } \\
\text { Post* }^{*}\end{array}$} & \multicolumn{2}{|r|}{ P-value } \\
\hline & Ante-partum & $\begin{array}{l}\text { Post-partum } \\
\text { (3 months) }\end{array}$ & & & $\begin{array}{r}\text { Ante vs. Non-pregnant } \\
\text { controlst }\end{array}$ & $\begin{array}{r}\text { Post vs. Non-pregnant } \\
\text { controlst }\end{array}$ \\
\hline$C_{\max }(n g / m L)$ & $\begin{array}{l}904.6 \\
{[363.9-} \\
2541.9]\end{array}$ & $\begin{array}{l}979.5 \\
{[414.5-} \\
2246.3]\end{array}$ & $\begin{array}{l}1284.7 \\
{[539.8-3259.4]}\end{array}$ & 0.89 & 0.24 & 0.090 \\
\hline $\mathrm{T}_{\max }(\mathrm{h})$ & $\begin{array}{l}1.50 \\
{[0.25-6.00]}\end{array}$ & $\begin{array}{l}1.50 \\
{[0.50-4.00]}\end{array}$ & $\begin{array}{l}1.52 \\
{[0.50-4.03]}\end{array}$ & 0.95 & 0.57 & 0.34 \\
\hline $\begin{array}{l}\mathrm{AUC}_{\text {all }}\left(\mathrm{ng}^{*} \mathrm{~h} /\right. \\
\mathrm{mL})\end{array}$ & $\begin{array}{l}1730.5 \\
{[1034.7-} \\
4085.5]\end{array}$ & $\begin{array}{l}2122.2 \\
{[1308.9-} \\
4054.9]\end{array}$ & $\begin{array}{l}2787.0 \\
{[1244.8-6363.5]}\end{array}$ & 0.0080 & 0.0018 & 0.021 \\
\hline $\begin{array}{l}\mathrm{AUC}_{\text {free }}\left(\mathrm{ng}^{*} \mathrm{~h} /\right. \\
\mathrm{mL})\end{array}$ & $\begin{array}{l}398.5 \\
{[138.7-663.9]}\end{array}$ & $\begin{array}{l}373.0 \\
{[186.5-708.3]}\end{array}$ & $\begin{array}{l}504.6 \\
{[197.9-1301.3]}\end{array}$ & 0.80 & 0.057 & 0.043 \\
\hline $\mathrm{CL} / \mathrm{F}(\mathrm{L} / \mathrm{h})$ & $\begin{array}{l}85.5 \\
{[36.2-142.9]}\end{array}$ & $\begin{array}{l}69.7 \\
{[36.5-113.0]}\end{array}$ & $\begin{array}{l}53.1 \\
{[23.2-118.8]}\end{array}$ & 0.0035 & 0.0018 & 0.021 \\
\hline $\mathrm{CL} / \mathrm{F}(\mathrm{L} / \mathrm{kg} / \mathrm{h})$ & $\begin{array}{l}1.39 \\
{[0.75-2.46]}\end{array}$ & $\begin{array}{l}1.26 \\
{[0.63-2.32]}\end{array}$ & $\begin{array}{l}1.07 \\
{[0.53-1.89]}\end{array}$ & 0.033 & 0.0025 & 0.011 \\
\hline$T 1 / 2(h)$ & $\begin{array}{l}1.28 \\
{[0.83-2.71]}\end{array}$ & $\begin{array}{l}1.63 \\
{[0.92-2.18]}\end{array}$ & $\begin{array}{l}1.41 \\
{[0.86-6.55]}\end{array}$ & 0.021 & 0.28 & 0.27 \\
\hline $\mathrm{Vd} / \mathrm{F}(\mathrm{L})$ & $\begin{array}{l}157.4 \\
{[59.9-335.9]}\end{array}$ & $\begin{array}{l}158.3 \\
{[66.0-332.7]}\end{array}$ & $\begin{array}{l}128.2 \\
{[38.5-400.1]}\end{array}$ & 0.82 & 0.098 & 0.071 \\
\hline Vd/F (L/kg) & $\begin{array}{l}2.84 \\
{[1.25-5.33]}\end{array}$ & $\begin{array}{l}3.00 \\
{[1.55-5.37]}\end{array}$ & $\begin{array}{l}2.45 \\
{[0.78-6.56]}\end{array}$ & 0.54 & 0.17 & 0.083 \\
\hline $\mathrm{FF}$ & $\begin{array}{l}0.21 \\
{[0.13-0.31]}\end{array}$ & $\begin{array}{l}0.19 \\
{[0.11-0.27]}\end{array}$ & $\begin{array}{l}0.18 \\
{[0.09-0.39]}\end{array}$ & 0.014 & 0.031 & 0.82 \\
\hline
\end{tabular}

Medians [range] and nonparametric comparison of groups.

* Wilcoxon signed rank test.

† Wilcoxon rank sum test. 
Table 4 DHA noncompartmental pharmacokinetic data in pregnant, postpartum, and non-pregnant women with Plasmodium falciparum infection

\begin{tabular}{|c|c|c|c|c|c|c|}
\hline \multirow[b]{2}{*}{ Parameters } & \multicolumn{2}{|c|}{ Antepartum vs. Postpartum* } & \multicolumn{2}{|c|}{ Antepartum vs. Non-pregnant controlst } & \multicolumn{2}{|c|}{ Postpartum vs. Non-pregnant controls $†$} \\
\hline & $\begin{array}{l}\text { Estimate } \\
(90 \% \mathrm{Cl})\end{array}$ & P-value & $\begin{array}{l}\text { Estimate } \\
(90 \% \mathrm{Cl})\end{array}$ & P-value & $\begin{array}{l}\text { Estimate } \\
(90 \% \mathrm{Cl})\end{array}$ & P-value \\
\hline$C_{\max }(\mathrm{ng} / \mathrm{mL})$ & $1.06(0.87,1.30)$ & 0.62 & $0.81(0.63,1.03)$ & 0.15 & $0.77(0.61,0.98)$ & 0.070 \\
\hline$T_{\max }(h)$ & $0.99(0.74,1.33)$ & 0.95 & $0.90(0.66,1.23)$ & 0.58 & $0.89(0.67,1.17)$ & 0.47 \\
\hline $\mathrm{AUC}_{\text {all }}\left(\mathrm{ng} \mathrm{h}^{*} \mathrm{~h} \mathrm{~mL}\right)$ & $0.87(0.77,0.98)$ & 0.064 & $0.68(0.57,0.81)$ & 0.0004 & $0.78(0.66,0.92)$ & 0.014 \\
\hline $\mathrm{AUC}_{\text {free }}\left(\mathrm{ng} \mathrm{n}^{*} \mathrm{~h} / \mathrm{mL}\right)$ & $0.99(0.85,1.15)$ & 0.92 & $0.78(0.63,0.95)$ & 0.039 & $0.78(0.65,0.95)$ & 0.038 \\
\hline $\mathrm{CL/F}(\mathrm{L} / \mathrm{h})$ & $1.21(1.09,1.33) \neq$ & 0.0075 & $1.48(1.24,1.76)$ & 0.0004 & $1.29(1.09,1.52)$ & 0.014 \\
\hline $\mathrm{CL} / \mathrm{F}(\mathrm{L} / \mathrm{kg} / \mathrm{h})$ & $1.16(1.03,1.29) \neq$ & 0.040 & $1.36(1.18,1.57)$ & 0.0008 & $1.24(1.07,1.44)$ & 0.016 \\
\hline$T 1 / 2(h)$ & $0.84(0.75,0.96)$ & 0.028 & $0.86(0.72,1.02)$ & 0.15 & $1.03(0.86,1.22)$ & 0.80 \\
\hline $\mathrm{Vd} / \mathrm{F}(\mathrm{L})$ & $0.97(0.83,1.14)$ & 0.74 & $1.26(1.00,1.60)$ & 0.097 & $1.32(1.04,1.67)$ & 0.056 \\
\hline $\mathrm{Vd} / \mathrm{F}(\mathrm{L} / \mathrm{kg})$ & $0.95(0.81,1.12)$ & 0.61 & $1.18(0.96,1.44)$ & 0.19 & $1.26(1.02,1.56)$ & 0.073 \\
\hline FF & $1.14(1.05,1.24)$ & 0.013 & $1.15(1.02,1.28)$ & 0.051 & $1.01(0.89,1.14)$ & 0.92 \\
\hline
\end{tabular}

Relative estimates ( $90 \% \mathrm{Cls}$ ) and parametric tests for group comparisons.

* Geometric mean antepartum:postpartum ratio and $90 \% \mathrm{Cl}$; 1-sample t-test on logged ratios.

† Ratio of geometric means and $90 \% \mathrm{Cl}$; 2-sample t-test on logged data.

₹ Mean antepartum:postpartum ratio and $90 \% \mathrm{Cl}$; 1-sample t-test on ratio.

reported in the literature $[23,24]$. This rapid disappearance precluded a comprehensive characterization of AS pharmacokinetics. However, given that DHA is the principle source of antimalarial activity following AS administration, the central focus of this pharmacokinetic analysis was the assessment of DHA pharmacokinetic alterations occurring during pregnancy. Pregnancy has been associated with substantial changes in the absorption, distribution, metabolism and excretion of a variety of drugs. High levels of progesterone may affect drug absorption. Increased plasma volume and altered drug binding protein concentrations can result in an increased volume of distribution. Pregnancy may increase metabolism of drugs, possibly through increased hepatic blood flow and increased free-fraction of drugs $[25,26]$. Decreased plasma concentrations of

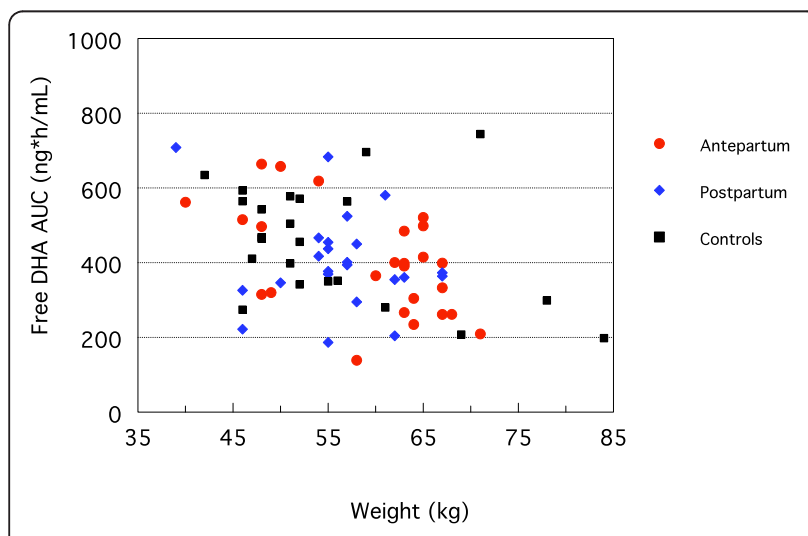

Figure 2 Unbound DHA AUC versus body weight, by subject group. therapeutic drugs in pregnancy can be a result of increased volume of distribution, increased pre-systemic clearance, increased metabolism or excretion, decreased protein binding, or any combination of these factors. Given the importance of maintaining therapeutic antimalarial blood levels, reductions in DHA blood levels resulting from such pregnancy-induced pharmacokinetic changes could potentially worsen clinical outcomes.

In this study, pregnant women had significantly lower plasma concentrations (AUC) of DHA s compared to non-pregnant controls. The $90 \% \mathrm{CI}$ for DHA $C_{\max }$, $A U C_{a l l}$ and $A C_{\text {free }}$ ratios in pregnancy compared to three months postpartum fell within the protocol specified 0.66-1.50 interval for the ratio. However, the median total and free AUCs for DHA in pregnant women were only $62 \%$ and $79 \%$ of the median total and free AUC for DHA in the non-pregnant controls. This decreased DHA exposure in pregnant women relative to non-pregnant controls is consistent with increased $\mathrm{CL} / \mathrm{F}$ and possibly increased $\mathrm{Vd} / \mathrm{F}$ during pregnancy.

There are several possible explanations for the apparent paradox of the similarity between DHA levels in pregnant women compared to levels in these women at three months postpartum but reduced levels compared to non-pregnant women controls. First, there are a variety of physiological and genetic factors that affect drug absorption, distribution and metabolism. A comparison of pharmacokinetic parameters in the same women during and after pregnancy mitigates the effect of most these potential confounders. Second, it is possible that many of the physiological changes that occur during pregnancy remain three months postpartum and continue to differentiate postpartum women from 
non-pregnant women. Only a few of the postpartum women were parasitaemic at the time of their repeat evaluation, which may also impact DHA pharmacokinetics. Finally, all women were lactating at three months post-partum; it is possible that lactation effects drug disposition.

Although the $90 \%$ confidence intervals for the DHA pharmacokinetic parameter ratios for the pregnant and postpartum subjects were within the $0.66-1.50$ equivalence interval, the median values of $\mathrm{AUC}_{\mathrm{all}}$ and $\mathrm{CL} / \mathrm{F}$, but not $\mathrm{Vd} / \mathrm{F}$, in the postpartum subjects were trending toward those in the non-pregnant parallel-group subjects. Therefore, if the non-pregnant control group pharmacokinetic parameter estimates are representative of the pre-pregnant pharmacokinetics of the pregnant/ post-partum group, then the return of pharmacokinetic parameters to presumed baseline may not have occurred completely at three months postpartum.

There are few previous pharmacokinetic studies in which postpartum subjects were compared intrasubject to the pregnant state. In a study of caffeine during and after pregnancy, the pharmacokinetics returned to predicted values in non-pregnant women within 4 days postpartum [27]. In another study, the estimated mean midazolam pharmacokinetic parameters, which reflected significantly decreased AUC and Cmax corresponding with increased apparent clearance during pregnancy, had returned to apparent normal in the postpartum period (weeks 6-10). In the same study, digoxin (p-glycoprotein substrate) pharmacokinetic parameters had also returned to normal by the post-partum period [28]. A multi-site, multi-country study on the pharmacokinetics of sulphadoxine and pyrimethamine during pregnancy and the postpartum period showed variable results by site and an inconsistency with pharmacokinetic parameters previously reported in the literature [29]. Lactation state has also been shown to modify alcohol pharmacokinetics in women [30]. Based on these examples, the time course to return to apparent "baseline" may, among other explanations, be chemotype-specific, lactation-state dependent, or pharmacogenomically-influenced. That there were inconsistencies reported for sulfadoxine-pyrimethamine both within- and between studies suggests that caution should be exercised in making dosing decisions based on a single study.

The presence of parasitaemia could potentially be contributing to the difference between the postpartum women and the non-pregnant controls, given that malaria infection itself may lead to altered pharmacokinetics [31]. Although all subjects in the present study, including postpartum subjects, were PCR-confirmed parasitaemic at screening prior to treatment with AS, only two of the postpartum women were parasitaemic by microscopy of Giemsa-stained blood films at the time of their pharmacokinetic assessments. Whether differences in parasitaemia influenced differences in pharmacokinetic parameter estimates is unknown. However, subjects were asymptomatic with low levels of parasites, which suggests that the influence of parasitaemia on pharmacokinetic parameter estimates may be minimal.

A prior study conducted by McGready et al in Thailand suggested that pregnancy was associated with decreased exposure to DHA, and increased DHA CL/F and $\mathrm{Vd} / \mathrm{F}$, as compared to results obtained in previous studies with non-pregnant adults [16]. This study evaluated the pharmacokinetics of DHA following AS administration using samples from the final day of a three day course of treatment for acute uncomplicated falciparum malaria in second and third trimester pregnant women. Their reported median value for DHA CL/F is higher than the values determined here, as well as higher than previously reported by Newton et al in non-pregnant patients with falciparum malaria during the acute or convalescent phase of infection [32]. The median DHA $\mathrm{Vd} / \mathrm{F}$ observed in the McGready study $(3.4 \mathrm{~L} / \mathrm{kg} ; 90 \%$ range 0.9-60.7) was also somewhat higher than the value observed in our analysis. This difference could, in part, be due to the fact that the women in the McGready study were given a different dosage of artesunate $(4 \mathrm{mg} / \mathrm{kg})$ in conjunction with Malarone ${ }^{\circledR}$. However, the substantially greater degree of variability in DHA CL/F and $\mathrm{Vd} / \mathrm{F}$ observed in the McGready study as compared to our study, as well as a lack of a postpartum or nonpregnant control group, complicates a direct comparison of findings.

Both the pregnant women and non-pregnant controls in our study displayed rapid clearance of parasitaemia following administration of the $200 \mathrm{mg}$ oral dose of AS. Differences in parasite clearance were not detected between the groups, despite the lower DHA AUC of the pregnant women. However, the possibility that a higher dose of AS in pregnancy, especially in larger women, would enhance the parasite clearance cannot be excluded.

No apparent AS toxicity to either mother or child was observed in this study. Concerns about the safety of artemisinin derivatives in pregnancy indicate that toxicity may be confined to the first trimester, with studies in rodents and primates suggesting that the artemisinin derivatives may be embryotoxic [14]. The positive safety findings of this study provide additional evidence that any toxicity risk of first trimester use may not extend into later periods of gestation.

\section{Conclusions}

Oral AS was found to be effective and without adverse effects in this study of Congolese pregnant women. No clinically relevant differences were seen in DHA 
pharmacokinetics between treated pregnant women and the same women three months postpartum. In contrast, the pregnant women had much lower AUCs than nonpregnant controls. These results suggest that further studies on the pharmacokinetics of AS in pregnant women are needed.

\section{Additional material}

Additional file 1: Changes in biochemical markers following AS

administration. All biochemical marker values given as mean \pm standard deviation.

\section{Acknowledgements}

We thank the staff of Maternité des Soeurs de Saint Marc de Kingasani, the community health workers of the Kingasani Health Zone and their MCZ, and the dedicated research staff from the Kinshasa School of Public Health for all their support and commitment in this research project. We thank RJ Nemeyer for the PCR analyses. We have a special thanks addressed to all the participants (pregnant and non-pregnant women) for their volunteered participation in our study.

A Global Network Study supported by grants from NICHD

\section{Author details}

${ }^{1}$ Kinshasa School of Public Health, Kinshasa, The Democratic Republic of Congo. ${ }^{2}$ UNC Gillings School of Global Public Health Department of Epidemiology, 3301 MHRCChapel Hill NC 27599-7435, USA. ${ }^{3}$ University of lowa, lowa City, lowa, USA. ${ }^{4}$ RTI International, Research Triangle Park, NC, USA. ${ }^{5}$ Crucell Holland B.V., Leiden The Netherlands. ${ }^{6}$ David Wesche Consulting LLC, Ann Arbor, MI, USA. 'University of California, San Diego, CA, USA. ${ }^{8}$ University of North Carolina at Chapel Hill, NC, USA. ${ }^{9}$ National Institute of Child Health and Human Development, NIH, Rockville, MD, USA.

\section{Authors' contributions}

$J H F, M K, E C, R W R$ and RSM contributed to designing the study protocol. MD, $\mathrm{MO}$, and JA wrote and produced clinical SOPs'. VL, JA and MO carried out ultrasound exams, biological sample and data collection. MK, EC, LF and MO carried out data analysis. MO, AKT and SRM drafted the initial manuscript. All the authors revised, read and approved the final manuscript.

\section{Competing interests}

The authors declare that they have no competing interests.

Received: 29 November 2010 Accepted: 28 February 2011

Published: 28 February 2011

\section{References}

1. World Health Organization: World Malaria Report 2009. Geneva, Switzerland: World Health Organization; 2009.

2. Shulman CE, Dorman EK, Bulmer JN: Malaria as a cause of severe anaemia in pregnancy. Lancet 2002, 360:494.

3. Menendez C, Ordi J, Ismail MR, Ventura PJ, Aponte JJ, Kahigwa E, Font F, Alonso PL: The impact of placental malaria on gestational age and birth weight. J Infect Dis 2000, 181:1740-1745.

4. Brabin B, Prinsen-Geerligs $P$, Verhoeff $F$, Kazembe $P$ : Anaemia prevention for reduction of mortality in mothers and children. Trans $R$ Soc Trop Med Hyg 2003, 97:36-38.

5. Steketee RW, Nahlen BL, Parise ME, Menendez C: The burden of malaria in pregnancy in malaria-endemic areas. Am J Trop Med Hyg 2001, 64(1-2 Suppl):28-35.

6. Menendez C, D'Alessandro U, ter Kuile FO: Reducing the burden of malaria in pregnancy by preventive strategies. Lancet Infect Dis 2007, 7:126-135.

7. World Health Organization: A strategic framework for malaria prevention and control during pregnancy in the African region. Brazzaville: WHO Regional Office for Africa; 2004.
8. Alker AP, Kazadi WM, Kutelemeni AK, Bloland PB, Tshefu AK, Meshnick SR: dhfr and dhps genotype and sulfadoxine-pyrimethamine treatment failure in children with falciparum malaria in the Democratic Republic of Congo. Trop Med Int Health 2008, 13:1384-1391.

9. Swarthout TD, van den Broek IV, Kayembe G, Montgomery J, Pota H, Roper C: Artesunate + amodiaquine and artesunate + sulphadoxinepyrimethamine for treatment of uncomplicated malaria in Democratic Republic of Congo: a clinical trial with determination of sulphadoxine and pyrimethamine-resistant haplotypes. Trop Med Int Health 2006, 11:1503-1511.

10. Cohuet S, Bonnet M, Van Herp M, Van Overmeir C, D'Alessandro U, Guthmann JP: Short report: molecular markers associated with Plasmodium falciparum resistance to sulfadoxine-pyrimethamine in the Democratic Republic of Congo. Am J Trop Med Hyg 2006, 75:152-154.

11. Sevene E, Gonzalez R, Menendez C: Current knowledge and challenges of antimalarial drugs for treatment and prevention in pregnancy. Expert Opin Pharmacother 2010, 11:1277-1293.

12. Ward SA, Sevene EJ, Hastings IM, Nosten F, McGready R: Antimalarial drugs and pregnancy: safety, pharmacokinetics, and pharmacovigilance. Lancet Infect Dis 2007, 7:136-144.

13. World Health Organization: Guidelines for the treatment of malaria. Geneva, Switzerland: World Health Organization; 22010.

14. Clark RL: Embryotoxicity of the artemisinin antimalarials and potential consequences for use in women in the first trimester. Reprod Toxicol 2009, 28:285-296.

15. McGready R, Stepniewska K, Lindegardh N, Ashley EA, La $Y$, Singhasivanon P, White NJ, Nosten F: The pharmacokinetics of artemether and lumefantrine in pregnant women with uncomplicated falciparum malaria. Eur J Clin Pharmacol 2006, 62:1021-1031.

16. McGready R, Stepniewska K, Ward SA, Cho T, Gilveray G, Looareesuwan S, White NJ, Nosten F: Pharmacokinetics of dihydroartemisinin following oral artesunate treatment of pregnant women with acute uncomplicated falciparum malaria. Eur J Clin Pharmacol 2006, 62:367-371.

17. Rijken MJ, McGready R, Boel ME, Barends M, Proux S, Pimanpanarak M, Singhasivanon $P$, Nosten F: Dihydroartemisinin-piperaquine rescue treatment of multidrug-resistant Plasmodium falciparum malaria in pregnancy: a preliminary report. Am J Trop Med Hyg 2008, 78:543-545.

18. Meshnick SR: Artemisinin: mechanisms of action, resistance and toxicity. Int J Parasitol 2002, 32:1655-1660.

19. Hadlock FP, Deter RL, Carpenter RJ, Park SK: Estimating fetal age: effect of head shape on BPD. AJR Am J Roentgenol 1981, 137:83-85.

20. Taylor SM, Juliano JJ, Trottman PA, Griffin JB, Landis SH, Kitsa P, Tshefu AK, Meshnick SR: High-throughput pooling and real-time PCR-based strategy for malaria detection. J Clin Microbiol 2010, 48:512-519.

21. Naik H, Murry DJ, Kirsch LE, Fleckenstein L: Development and validation of a high-performance liquid chromatography-mass spectroscopy assay for determination of artesunate and dihydroartemisinin in human plasma. $J$ Chromatogr B Analyt Technol Biomed Life Sci 2005, 816:233-242.

22. Angus BJ, Thaiaporn I, Chanthapadith K, Suputtamongkol Y, White NJ: Oral artesunate dose-response relationship in acute falciparum malaria. Antimicrob Agents Chemother 2002, 46:778-782.

23. Binh TQ, llett KF, Batty KT, Davis TM, Hung NC, Powell SM, Thu LT, Thien HV Phuong $\mathrm{HL}$, Phuong VD: Oral bioavailability of dihydroartemisinin in Vietnamese volunteers and in patients with falciparum malaria. $\mathrm{Br} J \mathrm{Clin}$ Pharmacol 2001, 51:541-546.

24. Batty KT, Thu LT, Davis TM, llett KF, Mai TX, Hung NC, Tien NP, Powell SM, Thien $\mathrm{HV}$, Binh $\mathrm{TQ}$, et al: A pharmacokinetic and pharmacodynamic study of intravenous vs oral artesunate in uncomplicated falciparum malaria. Br J Clin Pharmacol 1998, 45:123-129.

25. Frederiksen MC: Physiologic changes in pregnancy and their effect on drug disposition. Semin Perinatol 2001, 25:120-123.

26. Soldin OP, Mattison DR: Sex differences in pharmacokinetics and pharmacodynamics. Clin Pharmacokinet 2009, 48:143-157.

27. Brazier JL, Ritter J, Berland M, Khenfer D, Faucon G: Pharmacokinetics of caffeine during and after pregnancy. Dev Pharmacol Ther 1983, 6:315-322.

28. Hebert MF, Easterling TR, Kirby B, Carr DB, Buchanan ML, Rutherford T, Thummel KE, Fishbein DP, Unadkat JD: Effects of pregnancy on CYP3A and P-glycoprotein activities as measured by disposition of midazolam and digoxin: a University of Washington specialized center of research study. Clin Pharmacol Ther 2008, 84:248-253. 
29. Nyunt MM, Adam I, Kayentao K, van Dijk J, Thuma P, Mauff K, Little F, Cassam Y, Guirou E, Traore B, Doumbo O, Sullivan D, Smith P, Barnes Kl: Pharmacokinetics of sulfadoxine and pyrimethamine in intermittent preventive treatment of malaria in pregnancy. Clin Pharmacol Ther 2010, 87:226-234

30. Pepino MY, Steinmeyer AL, Mennella JA: Lactational state modifies alcohol pharmacokinetics in women. Alcohol Clin Exp Res 2007, 31:909-918.

31. Teja-Isavadharm P, Watt G, Eamsila C, Jongsakul K, Li Q, Keeratithakul G, Sirisopana N, Luesutthiviboon L, Brewer TG, Kyle DE: Comparative pharmacokinetics and effect kinetics of orally administered artesunate in healthy volunteers and patients with uncomplicated falciparum malaria. Am J Trop Med Hyg 2001, 65:717-721.

32. Newton P, Suputtamongkol $Y$, Teja-Isavadharm P, Pukrittayakamee $S$, Navaratnam V, Bates I, White N: Antimalarial bioavailability and disposition of artesunate in acute falciparum malaria. Antimicrob Agents Chemother 2000, 44:972-977.

doi:10.1186/1475-2875-10-49

Cite this article as: Onyamboko et al:: Pharmacokinetics and

pharmacodynamics of artesunate and dihydroartemisinin following oral treatment in pregnant women with asymptomatic Plasmodium falciparum infections in Kinshasa DRC. Malaria Journal 2011 10:49.

\section{Submit your next manuscript to BioMed Central} and take full advantage of:

- Convenient online submission

- Thorough peer review

- No space constraints or color figure charges

- Immediate publication on acceptance

- Inclusion in PubMed, CAS, Scopus and Google Scholar

- Research which is freely available for redistribution

Submit your manuscript at www.biomedcentral.com/submit
Biomed Central 